\title{
Development Towns in Israel: The Role of Community in Creating Ethnic Disparities in Labor Force Characteristics ${ }^{1}$
}

\author{
Seymour Spilerman \\ University of Wisconsin \\ Jack Habib \\ Brookdale Institute of Gerontology \\ and Adult Human Development, Jerusalem
}

\begin{abstract}
This paper investigates the contribution of community to ethnic stratification in Israel. We show that "development towns," a category of new settlements established to achieve population dispersal and immigrant absorption, have influenced $(a)$ the areal distributions of different ethnic (country-of-origin) groups, $(b)$ the tendency for each group to be concentrated in certain industries, and $(c)$ the occupational opportunities available to the members of an ethnic population. We also review the relevance of this analysis for understanding ethnic stratification in America.
\end{abstract}

\section{INTRODUCTION}

Urban communities in Israel have not attracted particular attention as research sites. In part, this is because there are more novel settlement patterns, found only in that country, such as the kibbutz (agricultural collective) and the moshav (small-holders' cooperative). These forms of rural community have been studied intensively, in regard to work organization (Spiro 1970), productivity of the economy (Barkai 1974), decision making (Cohen 1968), family structure (Talmon 1972; Weintraub and Shapira 1971), and child-rearing practices (Bettelheim 1969). It is the case, however, that Israeli urban settlements provide convenient sites for investigating a number of topics that are of interest to urban specialists, especially issues which relate to planned community development. The country's new towns, which were established in large numbers beginning in the late 1940s, permit one to evaluate the various strategies that have

\footnotetext{
1 This research was supported by the Brookdale Institute in Jerusalem and by the Institute for Research on Poverty at the University of Wisconsin. The first author would like to thank the Guggenheim Foundation and the Graduate School of the University of Wisconsin for funds to spend a year in Israel. Dr. Moshe Sicron, director of the Israel Central Bureau of Statistics, kindly made available to us a copy of the 1961 census tape. We also wish to acknowledge the comments by Professors Dov Weintraub and Judah Matras on an earlier version of this manuscript. We take responsibility, of course, for all views expressed in the paper.
} 


\section{American Journal of Sociology}

been employed in attempting to put together a viable community de novo: which industries can be implanted successfully in outlying areas, what mixes of settler backgrounds will produce socially integrated communities, and what kinds of local political institutions tend to operate effectively in the early stages of development of a new settlement.

The pattern of Israel's urban growth has been a matter of much concern to governmental authorities. At the time of the country's founding, in $1948,63 \%$ of the population was concentrated in three main citiesTel Aviv, Haifa, and Jerusalem - and in their immediate environs. Exacerbating this population imbalance, a vast immigration in the early years of the state threatened to create massive congestion in the urban centers, taxing their physical plants, the absorption potentials of their labor markets, and their social service capabilities, unless many of the immigrants could be motivated to settle outside the metropolitan regions.

Israel is a society with a considerable tradition of social planning and centralized decision making, dating to the imperatives of existence in the prestate period. The government, consequently, was in a position to undertake far-reaching decisions concerning population redistribution, and did so within months of the establishment of the state, committing extensive resources to this task. The instrument to accomplish population redistribution was to be a network of small and medium-sized urban settlements, located away from the densely populated coastal plain; these settlements have since become known as "development towns."

The new towns have been a focus of much concern. They are populated by recent immigrants, particularly from less developed lands. Many are isolated, outside the main stream of Israeli society geographically as well as socially. For these reasons, the settlements constitute, in many respects, a second and inferior Israel. What we wish to accomplish here in regard to the towns is twofold: we want to describe their evolution and their problems, and in doing so we intend to view them as strategic sites for addressing an issue in ethnic stratification - the effect which community can have in producing ethnic disparities in labor market characteristics. Specifically, we consider how the creation of these settlements has influenced $(a)$ the areal distributions of different ethnic (country-of-origin) groups, $(b)$ the tendency for each group to be concentrated in certain industries, and $(c)$ the occupational opportunities available to the members of an ethnic population. In the concluding section we review the relevance of these considerations for understanding the role of community in ethnic stratification in America.

\section{DEVELOPMENT TOWNS IN ISRAEL}

Settlement patterns in the Yishuv, the Jewish community in prestate Palestine, were influenced by an ideology which invested land reclamation and 
Jewish manual labor with great significance. The erection of agricultural settlements was therefore consistent with the tenets of labor Zionism, as well as having a basis in strategic considerations, in that it established Jewish rights to land in outlying regions through purchase and cultivation. Yet, as Cohen (1970, pp. 2-7) has remarked, in modern times the Jewish population in Palestine was never more than $30 \%$ rural, a fact that was ignored in early Zionist writings, in which little attention was given to the role of cities in a modern economy, or to their potential importance in the state which was to be created.

This situation changed abruptly following the establishment of Israel. In the three years subsequent to the termination of the British mandate, an influx of hundreds of thousands of immigrants, fleeing from persecution in Europe and the Arab countries, more than doubled the population of the state. In prior occupations, these immigrants had been predominantly artisans and small shopkeepers; they came to Israel as refugees, not out of an ideological conviction which might sustain them while adapting to the harsh life of an agricultural laborer. It was soon recognized by governmental authorities ${ }^{2}$ that residential quarters would have to be constructed in large numbers, in urban areas, to accommodate the immigrants. In order to relieve the congestion in Tel Aviv and Haifa resulting from very rapid population growth, and open the hinterland to settlement, industrialization, and mineral exploitation, the government adopted a policy of establishing new towns principally outside the periphery of Israel's metropolitan centers. $^{3}$

\footnotetext{
2 "The authorities did not turn their efforts to urban development out of their own free choice; this decision was forced upon them by the circumstances of immigration and settlement which emerged after the establishment of the state" (Cohen 1970, p. 33). Within two months of the creation of Israel, a National Planning Department was opened in the Ministry of Labor. Its principal objective was to initiate comprehensive settlement planning on a country-wide basis, as well as on a regional and local level (Brutzkus 1964, pp. 12-13).

The mechanics of immigrant settlement involves the cooperation of a private institution and several governmental ministries. The Jewish Agency, which fulfilled the tasks of refugee transportation and settlement during the mandate period, is still responsible for attracting new immigrants and for the initial stages of their absorption. The responsibility for planning and developing new towns is now divided mainly among three ministries-Labor, Housing, and Commerce and Industry-coordinated by an interministerial committee (Lichfield 1971, 1:3.2-3.10).

3 The dependence of immigrants on public agencies offered a unique opportunity for altering the settlement pattern existing at the creation of the state. Between 1949 and 1967 seven schemes for population dispersal were drawn up and revised by the Planning Department, each scheme looking 10-20 years into the future. As summarized in Lichfield (1971, 1:3.7), the thrust of the government's policy has been to $(a)$ reduce the urban concentration in the coastal belt between Tel Aviv and Haifa, $(b)$ disperse settlements throughout the country in order to develop the land, $(c)$ establish balanced regions through an integrated hierarchical structure of interdependent urban and rural settlements, and $(d)$ aid in absorbing and assimilating large numbers of immigrants by providing housing and employment.
} 


\section{American Journal of Sociology}

There is no consistent definition of a development town in the literature on Israeli settlements, though the intention is to signify urban settlements which lie outside metropolitan regions and which were established by design, since 1948, and with considerable governmental assistance. ${ }^{4}$ The 1961 Israel Census of Population, the most recent census available, does not employ this term and distinguishes instead between veteran and new communities. "New" communities include those founded after 1948, whether in outlying areas or in the suburban periphery, as well as a number of older settlements which have experienced the major portion of their population growth since the creation of Israel. According to the census, 38 new settlements ${ }^{5}$ existed in 1961, with a combined population of 398,000 . Other governmental agencies use the term "development town" to refer to new communities distant from metropolitan areas; yet there are differences with respect to the settlements each includes in this category. A report written for the Ministry of Labor (Smith 1972, p. 17) lists 24 communities ${ }^{6}$ with 246,000 residents in 1961. A report prepared for the Ministry of Housing (Lichfield 1971, 2:1) records 25 settlements, with 289,000 inhabitants in 1961. Nongovernmental researchers also differ in terminology and settlement classification: Spiegal (1966, p. 34) cites 24 "new towns," with a combined population of 271,000 in 1961 . Because suburban settlements are excluded, her specification corresponds to the notion of a development town. Amiran and Shachar (1969, table 4) list 28 development towns as of 1961 , with a total population of 312,000 .

The differences among these classifications result from decisions concerning which of the communities existing before 1948 should be consid-

4 In many instances the founding of a new town was preceded by comprehensive planning of physical facilities, industrial composition, and population growth. During the years of mass immigration, the tendency was to provide refugees who lacked skills or capital with housing and employment in these settlements. Various governmental agencies were involved in building the towns, and attracting industrial enterprises through the provision of tax incentives and loans on favorable terms. Politically, local municipal responsibility has generally been slow to develop, all decisions initially resting with the central government. For many years afterward a division of power over municipal affairs existed between the central and local authorities (Lichfield 1971, 1:4.12-4.15; Matras 1973, pp. 5-9).

5 This number refers to urban communities (31) and large villages (seven). An urban community is one containing more than 2,000 inhabitants and having at least twothirds of its labor force not engaged in agriculture. A large village is a settlement with more than 2,000 inhabitants which does not satisfy the industrial requirement. Large villages are included in our tabulation because five of the seven settlements appear on some list of development towns. Settlement definitions are reported in Israel Central Bureau of Statistics (1966, pp. 21-23; 1965, pp. 61-63).

6 The population figures which follow are adjusted to 1961 so that they will be comparable to the census values. For the same reason, settlements with fewer than 2,000 inhabitants in 1961 have been deleted from the tabulations. 
ered "developmental," and which settlements that were initially in this category should be viewed as having outgrown the label, in that they no longer receive extensive financial assistance from the central government. Where we are in a position to calculate indices from census data, we will use the list of communities proposed by Amiran and Shachar. Their definition covers settlements that were established after 1948, whether founded on entirely new sites or brought into being as a result of an influx of new populations into towns that had been vacated by Arab residents (Amiran and Shachar 1969, p. 1). Suburbs are omitted from the list, although one town (Tirat HaKarmel), which now is in the Haifa metropolitan region, is included. Also, they retain settlements that have progressed successfully, a consideration that is important, since we wish to discuss ethnic composition and industrial structure in the full array of communities which were planned to achieve population redistribution and immigrant absorption. Where we refer to statistics from other studies, the development towns to which the figures pertain will be somewhat different from Amiran and Shachar's list, in accordance with the comments in the preceding paragraph.

The growth of development towns, and the impact which these settlements have had on the distribution of the urban population, is reported in table 1 . The entries in the second row reveal that the considerable population expansion in the country since 1948 has been accompanied by an increase in proportion urban, from $73.3 \%$ to $84.4 \%$. The decline in the early years of the time series, incidentally, is due to the establishment of many development towns during this interval; initially, they were too small to be categorized as urban in the census. For our purpose, a more important trend concerns the massive population increase in the development towns and the population redistribution resulting from this growth (last row), even during a period when all urban communities were expanding. Indeed, the last two rows of the table, in combination, suggest that the redistribution policies of the government were most successful, since the proportion of the urban population residing outside the three metropolitan areas increased from $14 \%$ in 1948 to $48 \%$ in 1972 , with the bulk of this change deriving from the growth of development towns.

\section{The Concentration of Immigrant Groups in Development Towns}

The growth of new towns, and the population redistribution which was occasioned by this growth, did not arise principally from internal migration. Rather, new immigrants were encouraged to settle in development towns, with subsidized housing, low-interest loans, and the promise of employment serving as inducements. The outcome of this process was that, 


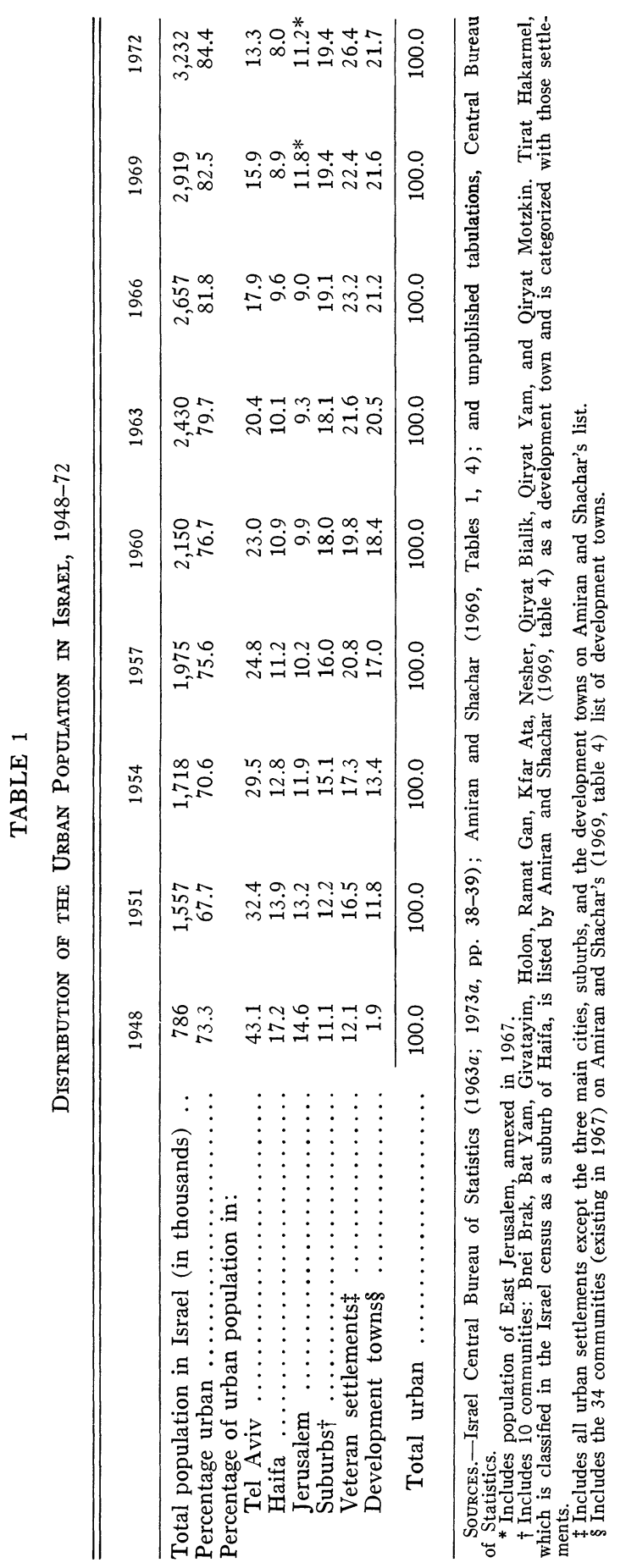


in $1961,67 \%$ of the population ${ }^{7}$ in development towns consisted of recent immigrants to the country, arrivals since 1948 , in comparison with $45 \%$ in the total Israeli population ( $36 \%$ in the main cities). Such great concentrations of recent immigrants, in communities that are also growing rapidly, could be expected to create massive problems of acculturation, and in the provision of housing, suitable jobs, and the many social services which a refugee population would require. Very great problems still exist in these towns; some will be discussed in the concluding section. Yet the settlement program was conducted within a framework of extensive assistance to the new communities by the central government. Also, the facts that Zionist ideology encouraged the ingathering of Jews, that many of the "veterans" were themselves immigrants in an earlier decade, and that Israeli culture was in the process of being molded during the initial years of the state, made for tolerance of the variety of life-styles brought by the immigrants, and a willingness to accept them as Israelis even while they were only marginally acculturated to the mores of the society.

We wish to focus on how development towns have patterned the industry affiliations of the immigrant groups and influenced their consequent occupational distributions. For this purpose it will be useful to delineate two aspects of residence location: representation of a population group in a settlement category, and variability of its concentration among settlements within the category. The latter factor speaks to the possibility that individual communities may "specialize" in particular industrial activities.

In regard to the first point, we note that not only are development towns places of concentration of recent immigrants, but that great differences exist between these settlements and other urban communities with respect to the origins of their foreign-born populations. Continent-of-origin figures are reported in columns 1 and 2 of table 2. From the entries in the two top panels it is evident that the population in development towns has been drawn, to a very considerable extent, from among Asian-African immigrants. They comprise $66 \%$ of the foreign born, versus $29 \%$ for Europeans. In reference to their percentages in Israel, Asian-Africans are overrepresented by a factor of 1.65 , Europeans underrepresented by a factor of $0.54(1.00=$ representation at the same rate as in the total population). This suggests that the industrial structures of the towns should be especially pertinent to understanding the labor force characteristics of Asian-African immigrants.

An equally important matter concerns differences among settlement types in regard to the variability of representation of the immigrant streams in the individual communities. This point refers to the fact that the continent-of-origin groups are not dispersed evenly, but tend to be concentrated

7 Since many of the Israeli born would be young children, the percentage foreign born in the adult population is much greater. 


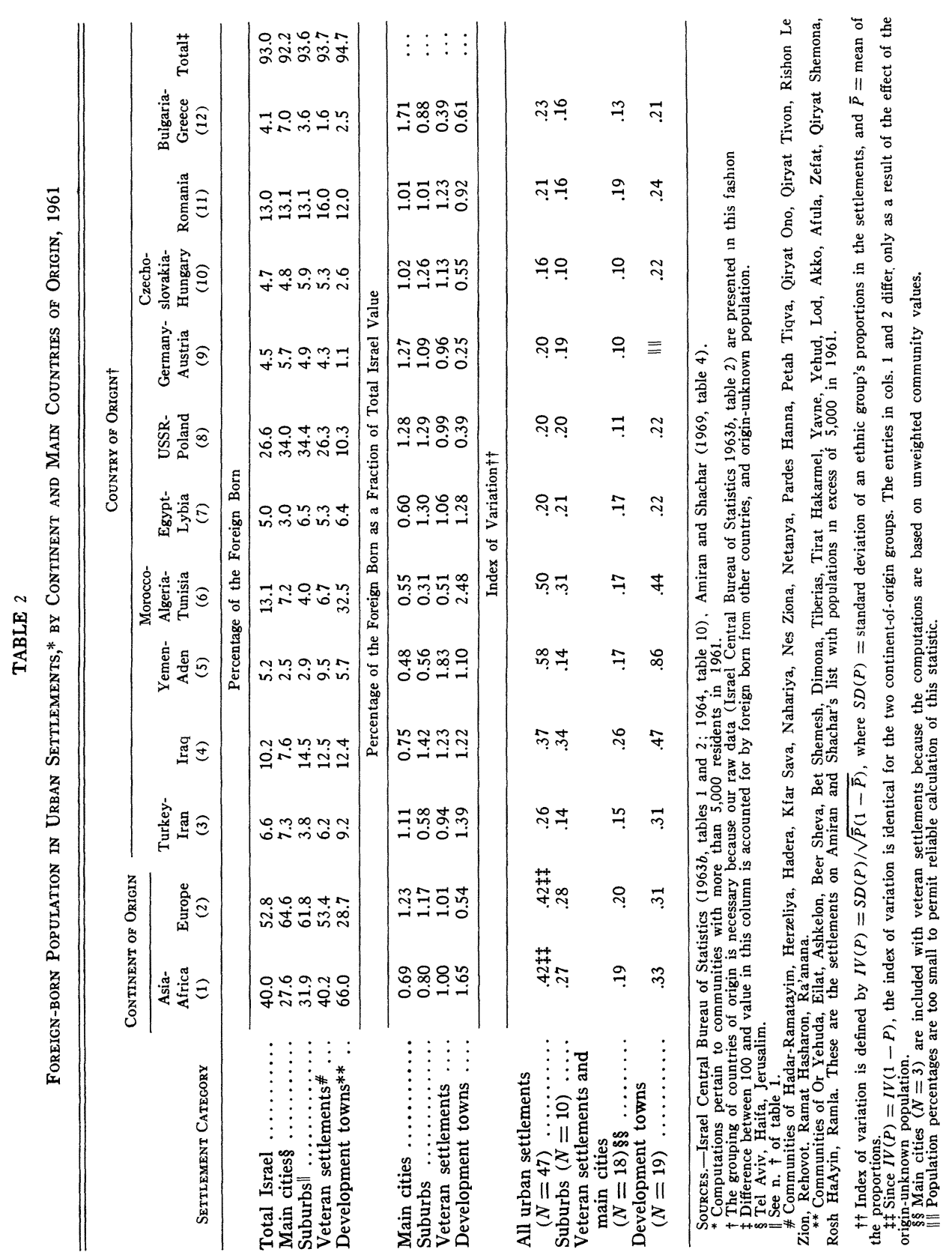


in some settlements and underrepresented in others. To measure variability we constructed an index that is analogous to the coefficient of variation (Stigler 1966, pp. 294-95). For an array of percentage values $\{p\}$ we assess variability by the statistic $I V(p)=S D(p) / \sqrt{\bar{p}(1-\bar{p})}$. This index compensates for the fact that the standard deviation of a percentage $(S D[p])$ is constrained to be small when the average is very large or very small, and thereby enables comparisons to be made among sets of percentages with different means. Indices of variation in the proportion AsianAfrican are presented for the various settlement categories in the bottom panel of column $1 .^{8}$ The large value for development towns (0.33) means that there are greater differences in ethnic composition among settlements in this category than among either veteran communities or suburban settlements. The relevance of this point is that disparities in industrial structure which exist among development towns may correspond to the variation in location of the continent groups, thereby exposing Asian-African and European settlers to very different industries and occupational opportunities.

Continent of origin is hardly a sensitive measure of cultural homogeneity, although this distinction is a salient one in Israeli life. Country of origin is a more important consideration; it signifies language and life-style, and it is at this level that ethnic identity is commonly specified. Columns 3-12 report representation values by settlement type for several ethnic groups (top panel), and these figures standardized by the respective national percentages (middle panel). It is apparent from the latter that each Asian-African group is overrepresented in development towns (entry $>1$ ) and, with few exceptions, underrepresented in metropolitan centers and suburbs. The reverse situation characterizes the locations of most European populations. Superimposed upon this pattern are some sizable differences among the individual ethnic groups: the concentration of MoroccanAlgerian-Tunisian immigrants in development towns is especially high (2.48 times their representation in Israel); the presence of Yemenites (1.10) indicates near equality to their percentage in the country, while immigrants from Germany-Austria are grossly underrepresented in the towns (0.25).

The variation in ethnic group concentration also speaks to the matter of labor force characteristics of these populations. The index values reported in the lower panel of table 2 show, in every instance, greater variability among development towns than among settlements in the other categories. It also appears that the individual Asian-African ethnics are apt to concentrate in certain towns, while the European groups are more evenly dispersed (compare cols. $3-7$ with $8-12$, last row). (Indeed, the

8 Since $I V(p)=I V(1-p)$, the index of variation is identical for the two continentof-origin groups, except for the effect of the origin-unknown population. 
index values for the Asian-African populations tend to be larger in every settlement category.) As we noted for the continent-of-origin groups, these observations suggest that whatever differences in industrial structure are present among development towns, they may have considerable impact on the industry affiliations of a number of the ethnics, by exposing them disproportionately to particular labor market opportunities. Any such effect should be greater for the Asian-African populations, because these groups are overrepresented in the towns, and because they exhibit a larger variation than Europeans in concentration by settlement.

\section{Time of Immigration and Concentration in} Particular Development Towns

Although it is a digression from our main theme-to show the impact of development towns on the industrial and occupational opportunities of the various ethnics - it is of interest to understand how the concentration of individual immigrant groups in certain settlements came about. The relevant facts are: $(a)$ the ethnic groups arrived in Israel in large numbers in different years, and $(b)$ the development towns were established and experienced their periods of maximum population growth at different times.

The tendency for the country-of-origin groups to differ in year of arrival to Israel is documented in table 3 . The first two columns report immigration to Israel by continent of origin; column 3 shows the ratio of European to Asia-African immigrants. There are several clusters of years during which new arrivals came disproportionately from one continent. The bulk of immigrants in the prestate period came from European countries, a trend which continued into the first two years of the state's existence, when the survivors of the Nazi extermination camps comprised the majority of newcomers. Following this period there was an eight-year interval when immigrants came from the Arab countries at approximately three times the rate from Europe. The ancient Jewish communities of Iraq, Yemen, and Aden moved to Israel, practically in their entireties, in these years. Several additional shifts followed in the dominance of a continent as a source of immigrants. These shifts frequently accompanied political upheavals in particular lands, and reflected the impact of those events on their Jewish populations. ${ }^{9}$

The dominant period of arrival of immigrants from the individual countries is more relevant to the issue of ethnic group concentration in different towns. In columns 4-7 we present immigration distributions for a few

\footnotetext{
9 Immigration from Morocco intensified after it achieved independence in 1956. Following the Hungarian revolution in 1956, tens of thousands of Jews fled to Austria; many eventually came to Israel. Recent immigration from Poland is related to the introduction of an anti-Semitic campaign following the Six-Day War in 1967.
} 
Development Towns in Israel

TABLE 3

Immigration to Israel by Continent and Selected Countries of Origin, 1932-72 (THOUSANDS)

\begin{tabular}{|c|c|c|c|c|c|c|c|}
\hline \multirow[b]{3}{*}{ YEAR } & \multicolumn{3}{|c|}{ Continent } & \multirow{2}{*}{\multicolumn{4}{|c|}{ Country }} \\
\hline & \multirow[b]{2}{*}{$\begin{array}{l}\text { Europe } \\
\text { (1) }\end{array}$} & \multirow{2}{*}{$\begin{array}{c}\text { Asia- } \\
\text { Africa } \\
(2)\end{array}$} & \multirow[b]{2}{*}{$\begin{array}{c}(1) /(2) \\
(3)\end{array}$} & & & & \\
\hline & & & & $\begin{array}{l}\text { Romania } \\
\text { (4) }\end{array}$ & $\begin{array}{c}\text { Bulgaria } \\
\text { (5) }\end{array}$ & $\begin{array}{c}\text { Iraq } \\
(6)\end{array}$ & $\begin{array}{c}\text { Iran } \\
(7)\end{array}$ \\
\hline $1932-38$ & 175.7 & 17.5 & 10.49 & 10.6 & 1.1 & 2.9 & 1.7 \\
\hline $1939-45 \ldots \ldots$ & 63.0 & 14.2 & 4.50 & 8.9 & 3.2 & 1.5 & 0.4 \\
\hline $1946-48 * \ldots \ldots$ & 48.5 & 2.0 & 24.25 & 16.2 & 1.2 & 0.0 & 0.0 \\
\hline $1948 \dagger-49 \ldots \ldots$ & 200.3 & 123.7 & 1.61 & 31.3 & 35.1 & 1.7 & 1.8 \\
\hline $1950-51 \ldots \ldots$ & 136.0 & 207.0 & 0.66 & 86.6 & 2.1 & 121.6 & 20.0 \\
\hline $1952-53 \ldots \ldots$ & 10.3 & 25.1 & 0.40 & 3.8 & 0.8 & 1.6 & 5.3 \\
\hline $1954-55 \ldots \ldots$ & 5.9 & 49.8 & 0.12 & 0.4 & 0.4 & 0.6 & 0.6 \\
\hline $1956-57 \ldots \ldots$ & 48.8 & 77.9 & 0.63 & 1.6 & 0.2 & 0.4 & 1.8 \\
\hline $1958-59 \ldots \ldots$ & 30.7 & 20.0 & 1.55 & 17.6 & 0.2 & 0.2 & 7.2 \\
\hline $1960-61 \ldots \ldots$ & 42.3 & 29.4 & 1.45 & 28.8 & 0.3 & 0.3 & 1.4 \\
\hline $1962-63 \ldots \ldots$ & 34.1 & 91.2 & 0.37 & 20.0 & 0.2 & 0.3 & 5.1 \\
\hline $1964-65 \ldots \ldots$ & 48.2 & 36.9 & 1.33 & 23.4 & 0.1 & 0.1 & 5.6 \\
\hline $1966-67 \ldots \ldots$ & 14.4 & 15.2 & 0.95 & $\$$ & $\ddagger$ & $\ddagger$ & 1.4 \\
\hline $1968-69 \ldots \ldots$ & 27.4 & 30.2 & 0.91 & $\ddagger$ & + & + & 3.1 \\
\hline $1970-71 \ldots \ldots$ & 54.2 & 23.7 & 2.28 & $\ddagger$ & $\$$ & $\$$ & 3.1 \\
\hline $1972 \ldots \ldots \ldots$ & 48.1 & 7.6 & 6.33 & $\$$ & $\ddagger$ & $\mp$ & 0.9 \\
\hline
\end{tabular}

Sources.-Sicron (1957, pp. 2, 6): Israel Central Bureau of Statistics (1973b, pp. 16-19).

* Until end of the mandate period.

$\uparrow$ From day of establishment of Israel (May 14, 1948).

$\$$ Data are not published.

countries of origin to illustrate the range of patterns that exist concerning time of arrival in Israel. These distributions show that for some ethnics (e.g., Bulgarians, Iraqis) immigration to Israel was compressed into a very brief interval, although the specific years may vary among the groups. Other ethnics (e.g., Iranians) show less concentration in time; their populations have arrived in sizable numbers over much of the lifetime of the state. Still other origin countries (e.g., Romania) exhibit arrival patterns which have several modes.

The tendency for period of immigration to have influenced the location of the individual ethnics in different development towns can be investigated by comparing the concentration of a group in the settlements that were growing rapidly during its years of maximum immigration, with the group's representation in all development towns. To pursue this matter we specified periods of substantial immigration to Israel for each ethnic group, and periods of rapid population growth for every town. A period of substantial immigration was defined as several adjacent years during which at least $50 \%$ of the group's population in 1961, the census year, arrived in the country. Alternatively, an ethnic group could have more than one period of substantial immigration if at least one-quarter of its population in 1961 arrived in each time period. The periods were specified so as to maximize 


\section{American Journal of Sociology}

differences among the ethnic groups in terms of this classification. That is, for analytic purposes, we wanted to define several time periods, with the individual ethnics dispersed among them. Due to annual fluctuations in the size of the total immigration stream, our intervals vary in duration from two to five years. The four time periods that were specified, together with the ethnics which experienced substantial immigration in each, are reported in table 4 .

TABLE 4

Ethnic Group Concentration in Development Towns,* by Period OF ARrival to IsRaEL, 1961

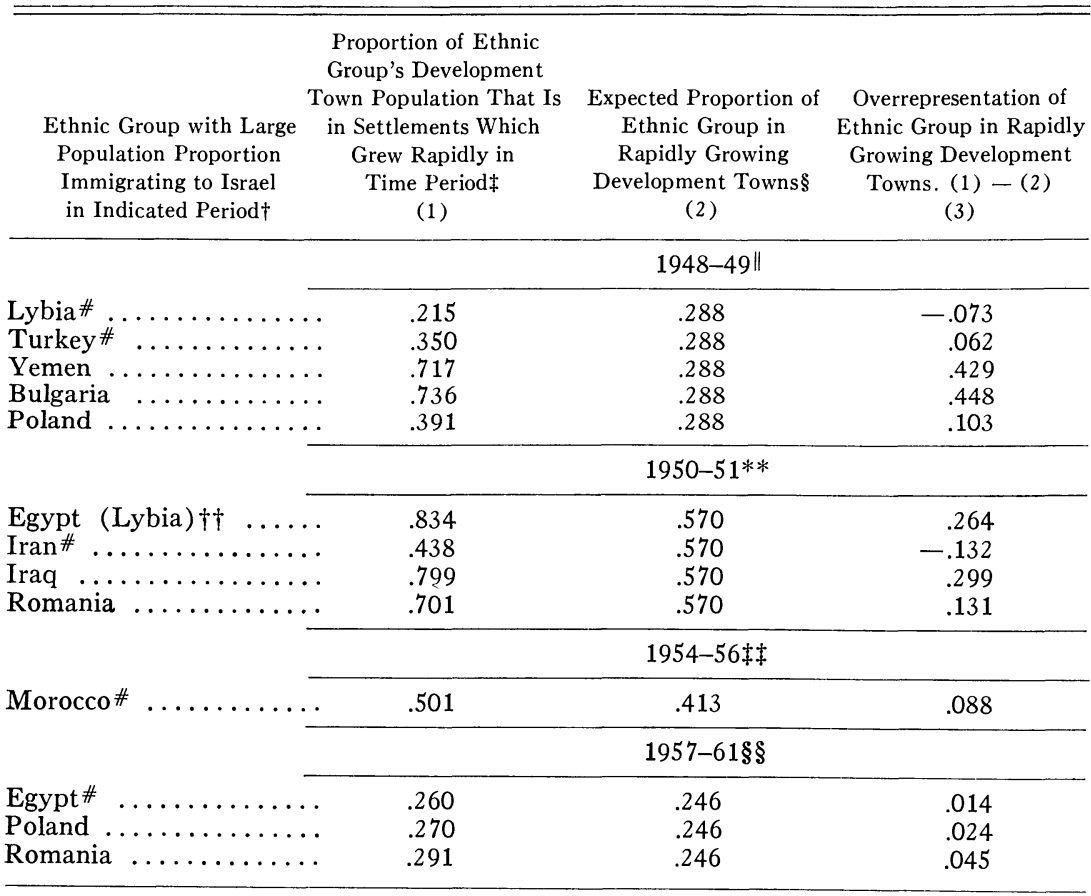

Sources.--Israel Central Bureau of Statistics (1973b, table 3; 1964, table 10; 1963b, table 2), Amiran and Shachar (1969, table 4).

* Computations pertain to the 19 development towns with populations exceeding 5,000 in 1961.

$\dagger$ "Large population proportion" is defined as more than one-half of the group's population in Israel in 1961 arriving in indicated period (if ethnic group appears in one time interval), or more than one-quarter of group's population arriving in the period (if ethnic group appears in two time intervals). $\$ A$ "rapidly growing town" is one with more than one-third of its 1961 population accounted for by expansion in the indicated period (if settlement appears in one time interval), or more than one-quarter of its population accounted for by expansion in the period (if settlement appears in more than one time interval).

\& Entry is the proportion of the total population in development towns in 1961 that is in settlements which grew rapidly in the time period.

|| Rapidly growing development towns in thịs period Akko, Lod, Ramla, Rosh HaAyin, Yehud.

\# In some census data used in our calculations (Israel Central Bureau of Statistics 1964, table 10) this ethnic group is paired with another which did not have a high immigration rate in the period.

** Rapidly growing development towns in this period. Akko, Afula, Ashkelon, Beer Sheva, Or Yehuda, Tiberias, Tirat Hakarmel, Zefat.

$\dagger \dagger$ Egypt and Lybia, which are grouped in the census data, each satisfied the criterion for inclusion in this time period.

\$ Rapidly growing development towns in this period: Ashkelon, Beer Sheva, Bet Shaan, Bet Shemesh, Dimona, Qiryat Shemona, Yavne.

$\S \S$ Rapidly growing development towns in this period: Beer Sheva, Dimona, Elat, Qiryat Gat. 
Rapidly growing development towns were defined as places which obtained at least one-third of their 1961 populations in the indicated time period. Alternatively, a town was considered to have multiple periods of rapid growth if it obtained at least $25 \%$ of its 1961 population in each of several intervals. Using these definitions we calculated the proportion of an ethnic group's development town population in 1961 which resided in settlements that were growing rapidly when its members had a high rate of immigration to Israel. This value is reported in column 1 of table 4 . In column 2 we present the proportion which would reside in these settlements if the group were represented equally in all development towns. Column 3 shows the difference between the entries in the preceding columns, and measures the extent of overrepresentation in the towns that were expanding rapidly.

These calculations support the argument that the ethnics tend to be concentrated in settlements which have growth histories that parallel their immigration distributions. Eleven of the 13 entries in column 3 are positive, indicating overrepresentation in rapidly expanding towns. Also, the two instances in which a column 3 entry is negative refer to situations where the ethnic group under consideration is paired in the census data with a second group, one lacking a high immigration rate in the referenced time period. In these cases our calculations cannot provide a sensitive test of the thesis. ${ }^{10}$

\section{THE INDUSTRY DISTRIBUTIONS AND OCCUPATIONAL STANDINGS OF THE ETHNIC GROUPS}

To this point our argument has been to the effect that as a consequence of a variety of arrival times in Israel by the individual ethnic groups, in combination with different periods of rapid population growth by the development towns, each immigrant population tends to be concentrated in particular settlements. The next consideration that we address concerns the tendency for a development town to "specialize" in certain industries, in the sense that its firms are grossly overrepresented in the labor force of the settlement, and the effect which this situation has on the industry affiliations of the individual ethnics.

There are a number of reasons for a lack of industrial diversity within development towns. First, most of the settlements are quite small; only six of the 28 on Amiran and Shachar's (1969, table 4) list had more than 15,000 inhabitants in 1961. This fact, alone, limits the number of industries

10 In contrast, three of the four largest entries in column 3 pertain to groups (Yemen, Bulgaria, Iraq) whose arrival patterns are characterized by "spikes"; that is, practically their entire populations emigrated during a very brief interval. This situation permits the cleanest test of the correspondence. 


\section{American Journal of Sociology}

which a town can support. Second, the national government has followed a policy of extending incentives for certain kinds of industries to locate in development towns. Third, the preferred industries tend to have large plants ${ }^{11}$ this also serves to reduce the variety of firms in a settlement.

Governmental encouragement of industry is carried out through a plan of financial incentives administered by the Ministry of Commerce and Industry. For locating in a development town, firms are granted tax reductions and low-interest loans for site acquisition, site development, onthe-job training of workers, and working capital (Lichfield 1971, 1:3.13). The kinds of industries that have been given preference are ones which either exploit the resources of a region-food-processing plants in agricultural locales, mining and chemical manufacturing in towns near the Dead Sea-or ones which, while neutral to location, are labor intensive and provide many jobs at a low initial capital cost. Textile manufacturing has been the most favored industry; the short training period for spinning and weaving jobs makes these tasks especially suitable for accommodating low-skill immigrants.

The impact of the factors which make for industrial concentration can be illustrated by reference to the economies of a few development towns. In Qiryat Shemona, 71\% of industrial employment is in textile manufacturing; this figure represents one-fourth of the total labor force in the city $^{12}$ (Zarchi and Shiskin 1972, pp. 61, 84). In Dimona, textile plants also dominate the manufacturing sector: $96 \%$ of industrial workers, representing $50 \%$ of the labor force, are in these enterprises. Ashqelon specializes in food processing ( $46 \%$ of industrial employment); Bet Shemesh manufactures transportation equipment $(40 \%$ of the industrial labor force); Afula weaves textiles (57\% of the industrial work force); and the economy of Yeruham, a new development town, is based principally on chemical and mineral processing (92\% of industrial employment). While it is true that the preceding examples depict extreme instances of unbalanced economic structures, they only exaggerate what is an evident tendency.

\footnotetext{
11 There is an evident tendency for plant size in development towns to exceed plant size in other settlements. In 1967, $18.2 \%$ of plants in development towns employed 100 or more persons; the comparable figure for the country was $4.4 \%$. In regard to the labor force, $69 \%$ of industrial employment in the towns was in these large plants, versus $43 \%$ for the country (Berler 1970 , p. 115). To a considerable extent, the concentration of large plants in development towns is due to the kinds of industries which have located there: food processing and packing, textile manufacturing, potash and chemical works, and cement products. Spiegal (1966, p. 51) adds that the government has preferred to negotiate with a few big enterprises rather than with many small ones.
}

12 This statistic is for 1971 . Other figures in this paragraph pertain to 1968 , and are from Lichfield (1971, 3:202, 160, 122, 41, 216). 
As a result of community differences in industrial composition, the individual ethnic groups tend to be overrepresented in certain activities. Yemenites are concentrated in textile manufacturing (three times their representation in the Israeli population), Moroccans are in mining (four times their representation), Lybians manufacture cement products (four times their representation), and immigrants from Algeria-Tunisia are employed disproportionately (by a factor of three) in wood product industries. ${ }^{13}$ The overrepresentation of those immigrant groups can be attributed to the particular development towns where they reside. Veteran settlements play much the same sort of role, but tend to expose European ethnics to certain industrial sectors. Germans are overrepresented (by a factor of two) in chemical and petroleum processing, an industry which has a major center in the Haifa Bay region, where this group is concentrated. Bulgarians, who reside principally in the Tel Aviv metropolitan area, are overrepresented (by a factor of two) in machinery and metal products manufacturing, an economic sector with a strong representation in this region.

To inquire in a more systematic fashion into the impact of community on the industry affiliations of the ethnic groups, indices of dissimilarity (Taeuber and Taeuber 1965, p. 236) were computed from the 1961 census tape to compare the industry distribution of each immigrant group with that of the urban population. For ethnic group $j$, this measure is defined by $I D_{j}=.50 \Sigma\left|P_{\imath \jmath}-P_{i .}\right|$, where $P_{i j}=$ the proportion of group $j$ 's urban population in industry $i, P_{i}=$ the proportion of the total urban population in industry $i$, and the subscript $i$ ranges over the two-digit census industry categories. The index $I D$, varies from 0 to 1 , and has an interpretation as the proportion of persons in ethnic group $j$ who would have to change their industry affiliations in order for the two distributions to be in agreement.

Index values for the individual ethnic groups are reported in column 1 of table 5. These figures document a rather consistent tendency for AsianAfrican ethnics to show greater discrepancies from the urban population in their industry distributions than is the norm for European groups. When continent of origin, as a summary measure, is considered, Asian-African immigrants exhibit almost twice the disparity of Europeans ${ }^{14}$ (.13 versus

13 Calculations are from the 1961 census tape, and refer to three-digit industry codes.

14 A problem exists in comparing the dissimilarities of subpopulations with a parent population. In the present application, the urban population consists of Asian-Africans $(28 \%)$, Europeans $(35 \%)$, and Israeli born plus continent unknown (37\%). Since Europeans constitute a larger percentage of the urban population than Asian-Africans, they should have a smaller index value. However, because the deleted group is the largest numerically, and because the two foreign-born groups are similar in size, the index values are not simply artifacts of the composition of the urban population. With respect to the individual ethnic groups, this consideration is of negligible importance, since each comprises a very small percentage of the urban population. 
TABLE 5

Degree of Disparity between Industry Distributions of the Ethnic Groups in Urban Areas and Total Urban Population, 1961

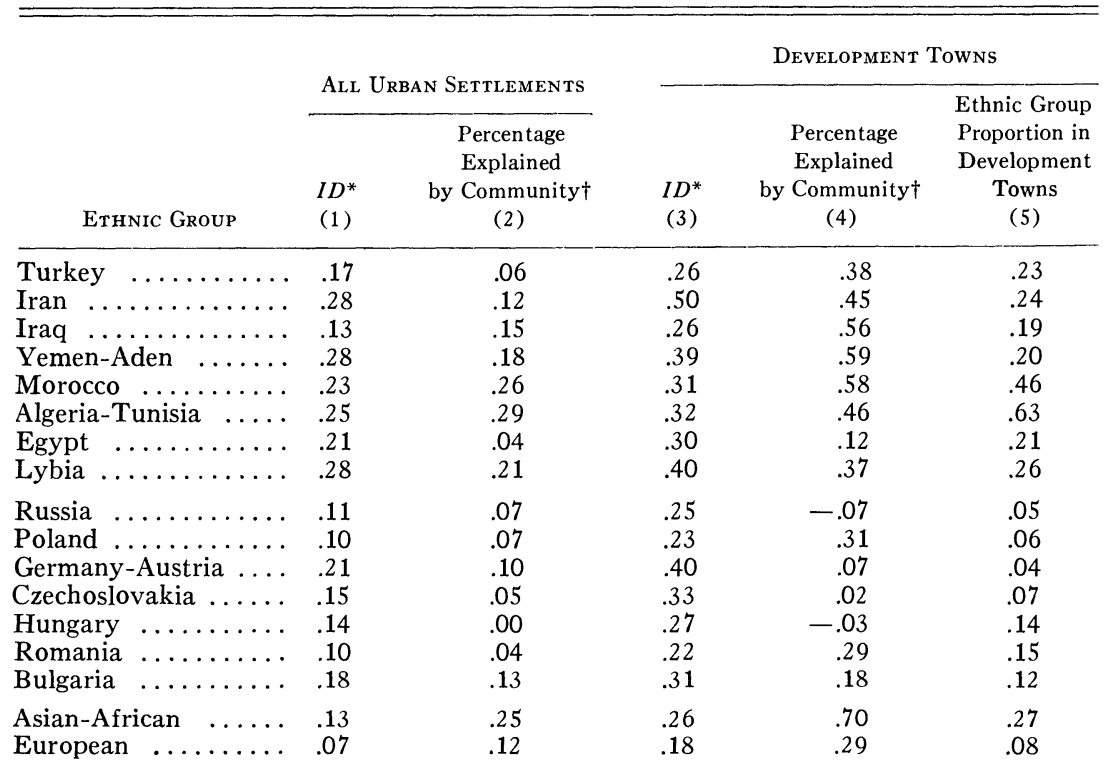

Source.-Computations are from the 1961 census tape, for males aged 14 and older, and pertain to communities with more than 5,000 inhabitants in 1961

* For ethnic group $j, I D_{j}=.50 \Sigma \mid P_{i j}-P_{i}$, where $P_{i j}=$ proportion of group $j$ 's urban population (development town population) in industry $i$, and $P_{\imath}$. $=$ proportion of the total urban population in industry $i$.

$\dagger$ Formula is $\left(I D_{j}-\hat{D}_{j}\right) / I D_{j}$. See text for details of this computation. Negative values should be interpreted as indicating zero importance of community.

.07). We will indicate, momentarily, that this difference is due to the greater representation of the former ethnics in development towns.

To ascertain the extent to which community industrial structure is responsible for the index values, we estimated an expected industry distribution $\left\{\hat{P}_{i j}\right\}$ for each ethnic group $j$, and calculated the degree to which the observed distribution for the group is accounted for by this set of estimates. The expected distribution was computed as a weighted average of the industry distribution in every community, the weights being the proportions of ethnic group j's urban population in the various settlements. These figures therefore report the representation which a group would have in different industries if its members were employed by them, in every community, at the same rates as the settlement's total labor force. The dissimilarity between the observed and expected industry distributions for group $j$ is specified by $\widehat{I D}_{j}=.50 \Sigma\left|P_{i j}-\hat{P}_{i j}\right|$, which measures the residual discrepancy, the amount not explained by community. The percentage re- 
duction in the index which can be attributed to community industrial structure is $\left(I D_{\jmath}-I D_{\jmath}\right) / I D_{j}$.

The index proportions which are explained by community, in the sense of the preceding discussion, are presented in column 2 of table 5 . There is an evident tendency for residence location to be more important for AsianAfrican groups than for the European ethnics. When continent of origin alone is considered, $25 \%$ of the discrepancy between the industry distributions of Asian-Africans and the total urban population can be attributed to the concentration of those immigrants in certain communities; for Europeans, the corresponding figure is $12 \%$. The percentages for the individual ethnic groups should also be compared with the indices of variation in settlement concentration (table 2, top row of lower panel). Despite the lack of full comparability between the ethnic categories in our two data sources, there is evidence that the effect of community is greater for groups having a large variation in settlement concentration. For instance, immigrants from Yemen-Aden and Morocco-Algeria-Tunisia have the highest index values of settlement concentration, and the largest percentages of their industry distributions accounted for by community. This correspondence is hardly surprising; it simply illustrates the mechanism we have been describing whereby community may create ethnic disparities in labor force characteristics.

What is the impact of development towns on the industry affiliations of the ethnic groups? To pursue this matter, the preceding calculations were repeated for the 19 development towns identified on the 1961 census tape. The index $I D_{j}$ now reports the difference between the industry distribution of group $j$ in the development towns, and the industry distribution of the total urban population. The results, which are presented in column 3 of table 5, reveal slightly larger index values for Asian-African ethnics than for Europeans; at the level of continent of origin, the respective figures are .26 and .18. A more pronounced effect concerns the disparity between the index value of an ethnic group in the development towns, and its value in all urban settlements (cols. 1 and 3 ). The figures for development towns are consistently larger, suggesting that these settlements expose their residents to industrial structures that differ considerably from the ones existing in other communities. ${ }^{15}$ This observation, together with the greater representation of Asian-African populations in development towns (col. 5), explains the manner by which the towns contribute to ethnic differences in industry affiliation (col.1).

15 Another way to convey this point is by noting the ID value of each settlement type. For all residents in a settlement category, as compared with the total urban population, the values are $.20, .13, .09$, and .09 , for development towns, veteran communities, suburbs, and main cities, respectively. Thus, the divergence from the urban population in industry structure is greatest for development towns. 


\section{American Journal of Sociology}

The degree to which the index values in column 3 can be attributed to the industrial composition of development towns is strikingly different for Asian-African and European ethnics. The proportions explained by community in the case of the former greatly exceed the proportions for the latter groups (col 4). ${ }^{16}$ At the level of continent of origin, the respective figures are .70 and .29 . It is also noteworthy that differences among the ethnic groups in the effect of community correspond to differences among them in degree of concentration in individual development towns (table 2, lower panel, last row). For instance, with regard to Asian-Africans, YemenAden immigrants are highest on both concentration by settlement and importance of community for explaining their industry distribution, while immigrants from Egypt-Lybia are lowest on both factors. The European groups exhibit little difference in degree of settlement concentration, although Romanians do have somewhat higher values on the two indices.

We conclude that the overrepresentation of Asian-African ethnics in development towns (which contain industries different from those common elsewhere in the country [n. 15]), and their further concentration in certain of these settlements, has served to expose them, to a disproportionate extent, to particular industrial opportunities. This situation is responsible for the larger disparities between their industry distributions and that of the total urban population, in comparison with European groups (table 5, col. 1), and for the greater importance of community in explaining their industry affiliations (col. 2).

\section{Impact of Residence Location on the Occupational}

Standings of the Ethnic Groups

The industrial configuration of a settlement is salient to labor force opportunity for a variety of reasons. Industry determines work satisfaction (Blauner 1964), seasonality of employment, and rate of promotion, as well as occupational composition. For the narrow purpose of understanding settlement differences in the latter factor, however, it is the case that the various industrial structures translate into much the same sort of occupational distribution for communities within each settlement category. In particular, despite the tendency for individual development towns to "specialize" in a given industrial activity-textiles, food processing, and mineral extraction being the most common-the different towns tend to have similar occupational distributions.

The reasons for this are not difficult to comprehend. We have already described the inducements proffered by the central government to firms

16 The negative values in this column indicate greater disparity from the industry distribution of the total urban population when the community distribution is considered. The most reasonable interpretation for these figures is as zeros. 
in certain industries, to motivate them to locate in development towns. The preference has tended to be for industries that are labor intensive and utilize low-skill work forces. Labor-intensive technologies create many jobs for a fixed initial capital investment, a matter of importance to a country with limited resources in the process of accommodating a large refugee population. Low-skill occupations permit immigrants from diverse cultural backgrounds to be assimilated into the labor force with a minimum of job retraining and language acquisition. With respect to the main urban centers, there is evidence from other studies (e.g., Galle 1963, p. 263) that major metropolitan places typically have many commercial and administrative functions, which entail sizable white-collar work forces.

In table 6, columns 1-4 report the average occupational distribution in each settlement type. ${ }^{17}$ The results for development towns and the main cities confirm our a priori notions. Development towns have few whitecollar workers $(22 \%$ of the labor force) while the main cities employ a great many $(49 \%)$, in comparison with the urban population $(41 \%)$. It

TABLE 6

Occupatronal Composition* ey Community Category, for Urban Settlements, 1961

\begin{tabular}{|c|c|c|c|c|c|c|c|}
\hline \multirow[b]{3}{*}{ Community Category } & \multicolumn{5}{|c|}{ Occupational Distribution $(\%) \dagger$} & \multirow{2}{*}{\multicolumn{2}{|c|}{$\begin{array}{l}\text { Occupational } \\
\text { Status Score } \$\end{array}$}} \\
\hline & \multirow{2}{*}{$\begin{array}{c}\text { Upper } \\
\text { White } \\
\text { Collar } \\
\text { (1) }\end{array}$} & \multirow{2}{*}{$\begin{array}{c}\text { Lower } \\
\text { White } \\
\text { Collar } \\
\text { (2) }\end{array}$} & \multirow{2}{*}{$\begin{array}{l}\text { Upper } \\
\text { Manual } \\
\text { (3) }\end{array}$} & \multirow{2}{*}{$\begin{array}{l}\text { Lower } \\
\text { Manual } \\
\text { (4) }\end{array}$} & \multirow[b]{2}{*}{ Total } & & \\
\hline & & & & & & $\begin{array}{l}\text { Observed } \\
\text { (5) }\end{array}$ & $\begin{array}{l}\text { Predicted } \\
\text { (6) }\end{array}$ \\
\hline Development towns & .09 & .13 & .39 & .39 & 1.00 & 97.5 & 101.3 \\
\hline Veteran settlements $\ldots$ & .14 & .18 & .40 & .28 & 1.00 & 104.0 & 106.4 \\
\hline Suburbs $\ldots \ldots \ldots \ldots \ldots$ & .15 & .23 & .42 & .20 & 1.00 & 111.7 & 110.0 \\
\hline Main cities $\ldots \ldots \ldots$. & .23 & .26 & .33 & .18 & 1.00 & 114.8 & 113.0 \\
\hline $\begin{array}{l}\text { All urban } \\
\text { settlements }\end{array}$ & .18 & .23 & .37 & .22 & 1.00 & 109.7 & 109.7 \\
\hline
\end{tabular}

Source.-Computations are from the 1961 census tape, for males aged 14 and older, and pertain to communities with more than 5,000 inhabitants in 1961 .

* Occupational categories are defined as follows. upper white collar-scientific and academic workers, other professional workers, administrators and managers, lower white collar-clerical and sales workers; upper manual - skilled workers in industry, mining, building, and skilled workers in agriculture; lower manual-unskilled workers in industry, transport, building, and skilled workers in agriculture; lower The components refer to the 1972 occupational classification, to which the 1961 census codes were The components refer to the 1972 occupational classification, to which the 1961 census codes were transformed (Israel Central Bureau of Statistics 1974, appendix B)

$\dagger$ Entries are unweighted averages of settlement values, with the exception of the last row, which 1 eports the occupational distribution of the urban population.

$\$$ Each of nine major occupational categories was indexed by its median earnings in 1972 (Israel, Central Bureau of Statistics 1973a, p. 344). "Observed" status scores are a weighted average of the earnings values, the weights being the proportions of the labor force from a settlement type in the occupations. "Predicted" status scores were calculated in the same manner except that the occupational distribution of a settlement was first estimated from its industry distribution, the estimation being made from an industry-by-occupation matrix for the entire urban population. Status scores are in units of from an industry-by-occupation matrix for the entire urban population. Status
Israeli currency (IL $\times 100)$ and reflect annual occupational earnings in 1972 .

17 Settlement occupational distributions were estimated from the occupational affiliations of residents in the respective communities. Our estimates, therefore, are least accurate for suburbs. 


\section{American Journal of Sociology}

is also the case that development towns have few skilled occupations, when this occupational category is viewed relative to the size of the lower manual work force. That is, while there are equal numbers of upper and lower manual positions, in other settlements the ratio of skilled to unskilled occupations is much higher, enhancing the mobility prospects there for lowerclass workers. Some implications of the restricted occupational opportunity in development towns are outlined in the next section.

We wish to make clear the structural underpinnings of the occupational differences among settlement types. The differences derive principally from the kinds of industries located in the communities, and relate only indirectly to the skill levels of the inhabitants. The final two columns of table 6 provide evidence for this contention. In column 5, "observed" occupational status scores are presented for each settlement type. These scores were calculated by classifying the occupations into nine major categories for which national earnings data are available, ${ }^{18}$ and computing a weighted average of the earnings figures, the weights being the labor force proportions in the categories. The resulting scores index occupational standing; the value for a community reflects only its occupational composition, not the quality of work by practitioners of an occupation or community differences in rate of pay for the same work. The entries indicate that occupational status varies considerably by settlement type, from a low of 97.5 for development towns to a high of 114.8 for the main cities. ${ }^{19}$ These figures, then, express the preceding distributional information in more summary form. In column 6 estimates of the occupational status scores are reported, the calculations being based on the occupational distributions characteristic of the various industries, ${ }^{20}$ and the industry composition of each settlement. These scores therefore report the status discrepancy that should exist among community types, given their industrial compositions. The estimated scores parallel the observed values, and reveal that 11.7 points from the 17.3-point range in occupational status is expected from industry differences among the settlements.

The fact that the occupational distributions of the communities can be

18 Earnings data are for 1972 (Israel Central Bureau of Statistics 1973a, p. 344). Information on income was not collected in the 1961 census. While earnings figures are available for years previous to 1972, they pertain to the one-digit categories of an old occupational classification, which is largely an industry classification, and show less dispersion than do the figures for the present occupational categories. The two-digit 1961 occupations were transformed to the 1972 codes using the occupational translation key in Israel Central Bureau of Statistics (1974, appendix B).

19 These calculations, and others in this section, were repeated with occupational status being indexed by average education in an occupation. The results were very similar to the ones reported in the paper.

20 An occupational distribution was constructed for each industry using data from the entire urban population. 
understood from a consideration of the kinds of industries they contain does not mean that the personal characteristics of residents are irrelevant to the determination of occupational composition. Indeed, we have argued that the industrial structures of development towns were deliberately planned with the needs of their prospective populations in mind. What a consideration of columns 5 and 6 reveals is that while the skill levels of the inhabitants may have been influential as initial causes in attracting certain kinds of enterprises, once an industrial base has been established the occupational structure of a settlement is an immediate resultant of its mix of industries. Also, since few industries have technologies which can accommodate much variety in occupational composition, a settlement cannot respond easily to changes in the skill and education levels of its residents.

The impact of community on the magnitude of ethnic differences in occupational status is reported in table 7 for the continent-of-origin groups. ${ }^{21}$ Columns 1 and 4 present occupational status scores for each ethnic group, by settlement category. These "observed" values were calculated in the same fashion as the entries in column 5 of table 6 , the sole difference being that the weights used in computing the occupational averages now pertain to proportions of the relevant ethnic group. The figures reveal sizable disparities for each group, over the community categories, with development towns showing the lowest status scores, and suburbs and

TABLE 7

Occupational Status* of the Continent-of-Origin Groups, by Community Category, 1961

\begin{tabular}{|c|c|c|c|c|c|c|}
\hline \multirow[b]{2}{*}{ Community Category } & \multicolumn{3}{|c|}{ ASIAN-AFrICAN } & \multicolumn{3}{|c|}{ EUROPEAN } \\
\hline & $\begin{array}{c}\text { Observed } \\
\text { Status } \\
\text { (1) }\end{array}$ & $\begin{array}{l}\text { Expected } \\
\text { Status } \\
(2)\end{array}$ & $\begin{array}{c}\text { Proportion } \\
\text { of Group's } \\
\text { Urban } \\
\text { Population } \\
\text { (3) }\end{array}$ & $\begin{array}{c}\text { Observed } \\
\text { Status } \\
(4)\end{array}$ & $\begin{array}{c}\text { Expected } \\
\text { Status } \\
(5)\end{array}$ & $\begin{array}{c}\text { Population } \\
\text { of Group's } \\
\text { Urban } \\
\text { Population } \\
\text { (6) }\end{array}$ \\
\hline Development towns .... & 91.0 & 96.6 & .27 & 106.4 & 98.1 & .08 \\
\hline Veteran settlements .... & 91.1 & 103.4 & .21 & 110.5 & 104.2 & .19 \\
\hline Suburbs $\ldots \ldots \ldots \ldots$ & 102.7 & 110.6 & .18 & 115.3 & 112.1 & .22 \\
\hline Main cities $\ldots \ldots \ldots \ldots$ & 99.8 & 114.9 & .34 & 119.7 & 114.7 & .51 \\
\hline $\begin{array}{l}\text { All urban } \\
\text { settlements } \ldots \ldots \ldots\end{array}$ & 96.2 & 106.6 & 1.00 & 115.9 & 110.8 & 1.00 \\
\hline
\end{tabular}

Source.-Computations are from the 1961 census tape, for males aged 14 and older, and pertain to communities with more than 5,000 inhabitants in 1961 .

* Status scores were computed in the manner described in $\mathrm{n}$. $\$$ of table 6 , except that the weights now refer to an ethnic group's proportions in the occupational categories. Scores are in units of Israeli currency $($ IL $\times 100)$, and reflect annual occupational earnings in 1972 .

21 The findings for the individual ethnic groups show only small differences from their continent means, and therefore are not presented separately. 


\section{American Journal of Sociology}

main cities the highest. Within each settlement type there also are substantial status differences between the immigrant groups: Europeans consistently have higher occupational standing than Asian-Africans. When all urban settlements are considered, a 19.7-point differential is obtained between the origin groups. What we wish to ascertain is the extent to which this gap is a consequence of the settlement patterns of the two ethnic groups.

Expected status scores were computed for each origin group by assuming that, in every community, its members had the same occupational distribution as the settlement's total population. This computation therefore indexes the degree to which an immigrant population is advantaged occupationally by its community locations. The expected scores are reported in columns 2 and 5, and reveal comparable occupational exposure patterns for the two ethnic groups within each settlement category. However, because Asian-Africans are overrepresented in development towns, while Europeans are concentrated in the main cities and suburbs (cols. 3 and 6), at the level of the total urban population a significant gap emerges in expected occupational status; the score for Asian-Africans is 106.6, and for Europeans it is 110.8 . This 4.2-point gap, which is attributable to different settlement locations by the two ethnics, accounts for $21 \%$ of the observed discrepancy in occupational status between the groups.

In actuality, this 4.2-point gap is an upper bound to the impact of community. Our computations have ignored resident characteristics, and thereby presume that any settlement differences in years of schooling or other job-related skills are, properly, the effects of community; for instance, lower educational attainment in development towns might be due to poor school facilities in these settlements. However, there is evidence (next section) that capable individuals tend to migrate from development towns. This means that individual attributes are, in part, a determinant of settlement location, rather than the reverse. If we adopt this formulation, the effect of community should be examined net of individual characteristics. While we cannot hold these factors constant using the preceding methodology, by means of a regression procedure an individual's occupational status was examined against terms for $(a)$ ethnic origin, $(b)$ education, age, and length of residence in Israel, and (c) 46 dummy terms for the settlements. The result was that the initial 19.7-point gap ${ }^{22}$ between Asian-African and European immigrants was reduced to 6.9 points by addition of the individual characteristics, and to 4.7 points by the introduction of the settlement terms. This last 2.2-point reduction, representing

22 In the regression formulation, the ethnic gap in occupational status appears as the difference between the $b$ coefficients for the two continent-of-origin groups (entered as dummy variables). The Israeli-born population is the deleted category. 
$11 \%$ of the initial status difference, is a lower bound to the effect of community. ${ }^{23}$

Settlement location by no means accounts for a major portion of the ethnic gap in occupational standing. Sizable disparities exist between the groups in education and occupationally relevant skills (Ben Porath 1973), and they are responsible for the larger part of the occupational differential. Nonetheless, the effect of settlement is not negligible. At the level of the individual ethnics, its importance is even greater in certain instances. For example, in terms of the more conservative calculation, a 3.8-point difference in occupational status is expected between immigrants from Russia and Algeria-Tunisia, in favor of the former, on the basis of the occupational opportunities available in the communities where each group resides. That this settlement effect is due largely to the different representations of these two ethnics in development towns may be seen from column 5 of table 5 .

\section{CONSEQUENCES OF INDUSTRIAL STRUCTURE FOR THE DEVELOPMENT TOWNS}

We have characterized development towns as locales in which few moderate-status positions are available, this limitation deriving from a concentration of low-skill industries in the settlements. Relating the occupational composition of the towns to their demographic features, we have suggested that the restricted occupational opportunity in these comunities is responsible, in part, for the disparities which exist in Israel in occupational standing between immigrants from European and those from nonEuropean countries; that is, the latter ethnics, being overrepresented in the towns, are exposed disproportionately to disadvantageous industrial contexts. Yet the impact of development towns on national-level indices of the ethnic gap is muted by the fact that even among Asian-Africans, only $27 \%$ of the population resides in this class of settlements. When we turn to a consideration of the social character of the towns themselves, however, the full impact of the initial decisions concerning the structure of their economies becomes evident.

There is merit to the contention that the government's policy to establish new towns in outlying areas, direct large numbers of immigrants to the settlements, and introduce in them principally labor-intensive, low-skill industries, constituted an efficient strategy by which a small country with

23 The persistence of a community effect, which we note here, means that, despite a high migration rate from development towns to communities with better work opportunities, many individuals, when confronted with a choice between career and ties to family and neighbors, do not choose to maximize occupational prospects. 


\section{American Journal of Sociology}

modest resources could cope with several pressing and related problems. First, immigrant absorption was a matter of urgency, not something that could be deferred or solved gradually, and the introduction of low-skill technologies facilitated their rapid incorporation into the labor force. A second objective furthered by the new towns was promotion of population redistribution and the opening of the hinterland to development. This was easier to achieve through encouraging new immigrants, who had few ties with communities in Israel, to settle in the towns, than through stimulating the migration of veteran Israelis from the country's metropolitan centers. Nevertheless, substantial disutilities can be associated with the new-town policy once a longer-range time perspective is adopted. Pertaining to this matter, we wish to discuss several immediate consequences of the labor force composition of development towns, as well as a number of derivative, second-order problems.

The direct consequences of limited opportunity are that immigrants who come to the towns with training which qualifies them for skilled manual or lower white-collar positions have difficulty in locating suitable work, and residents who begin their careers in low-ranked jobs have limited prospects for upward mobility. An indication of the seriousness of the blockage in occupational mobility, even for poorly educated persons, can be seen by noting that in the two medium-status categories underrepresented in the towns (skilled manual and lower white collar), ${ }^{24} 58 \%$ of the country's labor force in the former category, and $29 \%$ of the labor force in the latter, have eight or fewer years of education (Israel Central Bureau of Statistics $1973 a$, pp. 336-37). This means that it is not uncommon for capable individuals with little education to enter these occupations. To summarize, while the industries established in development towns may be appropriate to the skill level of the average immigrant, they severely constrain the occupational prospects of the better-educated or more motivated settlers.

Partly as a consequence of limited occupational opportunity, there has been considerable migration from development towns. A report on 21 towns (Israel Manpower Planning Authority 1964, p. 6) notes that $40 \%$ of their population in 1961 moved out of this settlement category in the succeeding two years; this figure was four times the national rate of interurban movement. There is also evidence that the migrants come from the more talented segment of the community: ${ }^{25}$ they are better educated than

\footnotetext{
24 "Skilled manual" refers to the census occupational category-skilled workers in industry, mining, building, and transport; and to part of the census category-agricultural workers. "Lower white collar" refers to two occupational categories-clerical and related workers, and sales workers (Israel Central Bureau of Statistics 1974).

25 Data are from tabulations prepared by the authors from the 1961 census tape. Occupational status is indexed by 1972 earnings figures for the one-digit census occupation categories. Facility with Hebrew is based on a census tape code which refers simultaneously to reading and writing competence.
} 
nonmigrants (7.6 years of schooling vs. 6.2), have higher current occupational status (103 vs. 96), are more facile with Hebrew ( $74 \%$ can read and write vs. 65\%), and have been in Israel for a longer period (11.4 years vs. 11.0). ${ }^{26}$ There is little migration to development towns from veteran settlements, which might offset this loss of capable residents. ${ }^{27}$ Rather, these towns have functioned as ports of entry for new immigrants to the country, providing them with temporary places of abode until they acquire the means to establish themselves in other communities. Those who remain tend to have modest occupational aspirations or require the housing subsidies and other kinds of assistance that are more readily available to residents of development towns. To put matters succinctly, the towns serve as "sinks" for less resourceful immigrants.

An additional process appears to operate in development towns within commuting distance of veteran settlements. Residents who are better qualified occupationally frequently obtain employment outside the towns and travel to work, much as if they lived in suburbs. From the 1961 census tape we calculated that, for the industrial labor force ${ }^{28}$ residing in development towns, mean education of males employed outside their settlements is 7.4 years, compared with 6.9 years for those residing and working in the towns. It is unclear from our data whether the existence of suitable employment in nearby communities permits development towns to retain these individuals, or whether it facilitates their eventual departure by enabling the withdrawal to be accomplished in stages. To some extent the latter process probably operates, since many of the settlements are not very attractive, and their inhabitants often have only a weak identification with community (Lichfield 1971, 1:6.3, 6.10). In this regard we point out that, alongside the departure of skilled manual and lower white-collar workers, development towns tend to have nonresident professional and administrative work forces (Smith 1972, p. 34). Teachers, social workers, and industrial managers choose to commute to work rather than reside in the towns. Our calculations from the 1961 census tape provide support-

\footnotetext{
26 We point out that the higher scores of migrants are not just a consequence of geographic mobility being more common among better-situated persons. Individuals who moved to another development town tend to have lower scores than migrants out of this settlement category. Averages for the former class of movers are: 7.1 years of schooling, 100.0 in current occupational status, $73 \%$ competent in Hebrew, and 10.9 years in Israel.

27 Amiran and Shachar (1969, p. 21) cite a net out-migration figure of 10,000 , during the interval 1956-61, from the census category "new urban settlements" (which includes approximately one-half the population in development towns). Lichfield (1971, $1: 6.2$ ) reports a net out-migration of 43,800 , between the years 1961 and 1967, from his list of development towns.

28 Several development towns, in outlying areas, also supply agricultural workers. Since we are discussing the impact of the labor market in neighboring settlements, agricultural employment is deleted from this comparison.
} 
ing evidence for this residence style among white-collar workers: educational attainment by nonresidents employed in development towns is 10.0 years of schooling, versus 6.6 years for inhabitants of the towns.

These processes are responsible for the indirect effects of industrial structure that we wish to document. The inability of the settlements to retain their more resourceful and better-acculturated inhabitants, or attract comparable persons from other Israeli communities in substantial numbers, has meant that the settlers who remain tend to have high rates of dependency and related social problems. In 1963, 11.6\% of families in development towns received continuous economic help, in comparison with $4.4 \%$ in the total population. For all forms of assistance, the respective figures were $34.5 \%$ and $17.4 \%$ (Israel Manpower Planning Authority 1964 , p. 26). With regard to participation in education by youth, in the 14-17-year age group, $41 \%$ in development towns study full-time in some educational institution, compared with $68 \%$ in the entire country (Israel Manpower Planning Authority 1964, p. 11). Delinquency statistics are consistent with this picture. Using data from the Israel Ministry of Welfare's (1972) handbook of community characteristics, we calculated an incidence rate of 26.6 per 1,000 in the age group 9-16 for the 19 development towns used in the previous computations. This figure compares with 14.3 for the country, and 16.4 for the three main cities.

Even if the rates of incurring social problems in development towns by the ethnic and class groupings residing there were not greater than the rates these same populations exhibit in other communities, the mere fact of concentration of less resourceful families creates undesirable consequences. The low representation of moderate-status individuals in the towns and their high population turnover mean that local leadership tends to be weak $^{29}$ (Lichfield 1971, 1:63), that the schools are not centers of excellence, and that the clientele capable of supporting cultural activities is small. Despite grants-in-aid from the central government, these settlements are hard pressed to collect adequate tax monies to provide for the manifold needs of their lower-class populations (Lichfield 1971, 1:5.16), not to mention the amenities which can make a community an attractive place of residence. Finally, because development towns are contexts in which dependency is common, there is a serious risk that it will become an approved life-style. ${ }^{30}$

29 At the same time, according to Aronoff (1973, pp. 42-44), the concentration of Asian-African populations in development towns has facilitated the emergence of political leadership in these ethnic groups. Since their populations dominate the electorates, local ethnic leaders have a more secure political base in the towns than in veteran settlements.

30 In a recent study of factors which influence requests for a certain welfare allowance, Bar Yosef, Schild, and Varshar (1974) report that, after controls for personal need, 
To clarify the preceding comments, and place them in perspective in relation to long-range prospects for the towns, we must stress two points. First, we have discussed development towns as if they formed a homogeneous settlement category with regard to occupational composition and the presence of derivative problems. This is a reasonable first approximation to the reality, and an efficient analytic strategy considering that our interest is to elucidate the relation between community and ethnic stratification, and document the particular role played by industrial structure. However, it means ignoring the many differentiating mechanisms which have resulted in a few development towns constituting cases of successful progress, in that they attract settlers from diverse population groups via internal migration, retain their more talented residents, and have either acquired a diversified industrial base or were founded originally around industries which utilize a greater array of occupational skills than is the norm in the majority of the towns.

Beersheva, Ashdod, and Arad are examples of successful development towns. Beersheva is now a regional center for southern Israel; it has a university, provides medical and commercial services for the surrounding region, and is able to support a varied white-collar labor force. Ashdod is a major seaport: Workers in shipping are well paid; also, the town has attracted ancillary manufacturing, transportation, and commercial firms that find it advantageous to be located in a maritime center. Arad is an isolated community near the Dead Sea which has been built around mineral extraction, chemical processing, and metal fabrication industries. These activities require engineers, technicians, and skilled craftsmen. Because of the settlement's isolation, these personnel, together with teachers, social workers, and others who provide professional services in the town, must live there, and consequently have a vested interest in its progress. Arad, in addition, is advantaged by social composition; a majority of its residents are Israeli born, and lack the many adjustment problems which confront new immigrants. Differentiating processes of considerable import therefore operate, and some settlements are following satisfactory development trajectories. However, a detailed consideration of these matters is outside the scope of this report.

A second qualification concerns the fact that we are examining the towns at a very early point in their histories. The bulk of our data are from the 1961 Census of Population; thus no development town is older than 13 years, at least in its modern phase. Most are very small, having less than 10,000 inhabitants, and their unbalanced industrial character stems partly from this size factor. However, because governmental policy is to encourage further growth, and because the immigrants now arriving in

knowledge about the allowance, and various individual characteristics, residence in a development town has a strong, positive effect on application. 


\section{American Journal of Sociology}

Israel come predominately from European countries and are better educated than the earlier refugees, conditions exist for altering the industrial composition of the settlements. The amount of high-technology industry that would have to be introduced to provide reasonably balanced occupational structures is not at present very great, and could be organized around the skills of the new immigrants in combination with a modest number of Israelis who might be attracted from veteran settlements.

\section{RELEVANCE OF THIS ANALYSIS FOR ETHNIC STRATIFICATION} IN THE UNITED STATES

The processes we have described are very visible in Israel because of the huge immigration inflow this country has experienced in a brief time interval - far exceeding the rate of growth of the American population from immigration in any similar period-and because the government's espoused intention has been to settle the immigrants in new towns. Nonetheless, the importance of community for explaining ethnic stratification in the United States is also considerable, although the mechanisms that have brought immigrant groups to certain sections of the country, and to particular communities, are not identical with the ones which have operated in Israel.

The sorts of mechanisms that have generated ethnic concentration by region and community in America concern time of arrival, route of travel, and degree of affinity of a group for its own kind. The first factor is associated with the processes we have described in connection with ethnic concentration in Israel. Immigrants from various lands came to America in different decades; and time of arrival correlates with location of the western frontier and, consequently, with period of settlement of a geographic region. Route of travel is a consideration in explaining the concentration of certain groups-French-Canadians, Mexicans, and Chinesewho came via routes that were not followed by the majority of immigrants. These ethnics tend to be overrepresented in the states that border their ports of entry.

The preference of individuals from the same country of origin to live in proximity to their own kind is also responsible for generating ethnic concentration, although this factor does not explain where in American a group will choose to reside. Breton (1964) suggested that immigrants who are different from the receiving population on a number of dimensionslanguage, religion, cultural traditions - are likely to settle together in a community in order to constitute a clientele of sufficient size to support ethnic churches, schools, restaurants, newspapers, and Landsmanshaften. Once the initial migrants have established themselves in particular cities, 
chosen for whatever reason, subsequent immigrants from the country of origin tend to travel to the same settlements.

As a consequence of these processes, the correspondence of ethnicity with geographic region and community is quite strong. Scandinavians and Germans are concentrated in the Midwest; French-Canadians are located in northern New England; Italians are in southern New England and in the Mid-Atlantic states; and Jews, a heavily urban group, reside principally in New York City and Chicago. To cite instances of extreme ethnic concentration in states, 1920 census data on the foreign born reveal that Norwegians were represented in North Dakota at 15 times their national rate; French-Canadians were concentrated in New Hampshire at 27 times their rate in the country; and Mexicans were overrepresented in Arizona by a factor of 41 (Hutchinson 1956, pp. 34-48). It is also the case that first-generation American born continue to reside in the geographic regions of their parents; 1950 census data on natives of foreign or mixed parentage show representation rates of 19,27 , and 11 for the preceding three groups, in their respective states (Hutchinson 1956, pp. 39-43).

The persistence of ethnic concentration means that regional and community differences in industry location will have a stable impact on ethnic opportunity. There are striking differences among the immigrant groups in industry affiliation. This is principally a consequence of the industrial composition in the settlements where a group is concentrated, although the ethnic populations are themselves responsible for introducing several industries into America - ready-made apparel manufacturing, for instance, is associated with Jewish immigrants (Hapgood 1966, p. 10). To illustrate the tendency toward ethnic concentration by industry, according to 1950 census data on the foreign born, French-Canadians are employed in textile mills (a New England industry) at seven times their representation in the population. Mexicans work in farming at 11 times their expected rate, and in food processing at three times the expected rate (both industries have extensive operations in the Southwest and far west). Czechoslovakian and Yugoslavian immigrants are employed in primary metal processing at four times their representations in the country; these groups have large populations in Pennsylvania, Ohio, and Illinois, which are centers of ferrous metalworks (Hutchinson 1956, pp. 224-31). ${ }^{31}$

Industry affiliation is an important consideration in the analysis of occupational standing and mobility for several reasons. Industries differ in technology and, as a consequence, in mix of occupations. Textile manufacturing and food processing, for instance, contain few skilled manual positions, while the majority of the blue-collar work force in printing and

31 Industry concentration figures are based on data for operatives, except in the case of Mexicans in farming, for whom farm laborer figures were used. 
in aircraft manufacturing is classified as skilled (U.S. Bureau of the Census 1963, pp. 506-12). The occupational distribution in an industry is one determinant of the mobility prospects facing an individual, and constrains his advancement to a greater or lesser extent, depending on the shape of the distribution, as long as he remains employed in that sector of the economy. ${ }^{32}$ Where communities are centers of a particular industrial activity, the occupational composition of the dominant industry has an even more pervasive effect on labor market opportunity; indeed, this is the situation that exists in many development towns in Israel.

Industries differ in other respects which can influence an individual's occupational mobility prospects. In some, the firms characteristically fill their upper-manual positions by promotion from below; in other industries a craft model is the norm, which permits little possibility for upward movement. Demographic features of an industry are also relevant to understanding mobility opportunity: some industries are expanding, and create new upper-manual and white-collar positions which might be filled through promotion; others are stable or declining in employment, and present limited promotion prospects. Finally, industries differ in the age composition of their employees, a consideration relevant to mobility, as it specifies the amount of promotion and replacement hiring that will take place in the short-term future.

It is unfortunate that industry and community characteristics have been neglected in the main thrust of research on status attainment, which has focused exclusively on individual-level variables. This omission is especially serious in the study of ethnic stratification, since, as we have documented, ethnic groups tend to be concentrated by region and settlement, and are therefore exposed to different industrial structures. Analyses of occupational standing have commonly attributed the ethnic effects which remain after controls for individual characteristics (father's SES, respondent's education and status of first job, etc.) to cultural background or motivational differences among the groups (Duncan and Featherman 1972). While we have no reason to doubt the salience of such factors for understanding ethnic stratification, we do suggest that they are confounded in the residual ethnic terms with substantial industry and community effects.

\section{REFERENCES}

Amiran, D. K. H., and A. Shachar. 1969. Development Towns in Israel. Jerusalem: Hebrew University.

32 Change of industry, indeed change of firm, is hardly a decision that can be made easily, except by the young, in response to the availability of better occupational prospects with a different employer. Workers accumulate pension rights, seniority toward job security, and other vested interests which are not transferable. 


\section{Development Towns in Israel}

Aronoff, Myron J. 1973. "Development Towns in Israel." In Israel: Social Structure and Change, edited by Michael Curtis and Mordecai Chertoff. New Brunswick: Transaction Books.

Barkai, Haim. 1974. "A Model of Kibbutz Production and Factor Allocation." Discussion Paper no. 742. Jerusalem: Falk Institute.

Bar Yosef, Rivka, Gile Schild, and Yudith Varshar. 1974. "Research on the Economic Situation of Large Families at the Time of the War." In Hebrew, mimeographed. Jerusalem: Work and Welfare Research Institute, Hebrew University.

Ben Porath, Yoram. 1973. "On East-West Differences in Occupational Structure in Israel." In Israel: Social Structure and Change, edited by Michael Curtis and Mordecai Chertoff. New Brunswick: Transaction Books.

Berler, Alexander. 1970. New Towns in Israel. Jerusalem: Israel Universities Press.

Bettelheim, Bruno. 1969. Children of the Dream. New York: Macmillan.

Blauner, Robert. 1964. Alienation and Freedom. Chicago: University of Chicago Press.

Breton, Raymond. 1964. "Institutional Completeness of Ethnic Communities and the Personal Relations of Immigrants." American Journal of Sociology 70 (September): 193-205.

Brutzkus, Eliezer. 1964. Physical Planning in Israel. Jerusalem: E. Brutzkus.

Cohen, Erik. 1968. "A Comparative Study of the Political Institutions of Collective Settlements in Israel." Mimeographed. Jerusalem: Department of Sociology, Hebrew University.

1970. The City in the Zionist Ideology. Jerusalem: Institute of Urban and Regional Studies, Hebrew University.

Duncan, Otis D., and David L. Featherman. 1972. "Psychological and Cultural Factors in the Process of Occupational Achievement." Social Science Research 1 (June): $121-45$.

Galle, Omer R. 1963. "Occupational Composition and the Metropolitan Hierarchy: The Inter- and Intra-Metropolitan Division of Labor." American Journal of Sociology 69 (November): 260-69.

Hapgood, Hutchins. 1966. The Spirit of the Ghetto. New York: Schocken.

Hutchinson, E. P. 1956. Immigrants and Their Children, 1850-1950. New York: Wiley.

Israel Central Bureau of Statistics. 1963a. Population and Housing Census 1961: The Settlements of Israel, Part 1. Publication no. 10. Jerusalem: Central Bureau of Statistics.

- 1963b. Population and Housing Census 1961 - The Settlements of Israel, Part 3. Publication no. 12. Jerusalem: Central Bureau of Statistics.

- 1964. Population and Housing Census 1961: The Settlements of Israel, Part 4. Publication no. 18. Jerusalem: Central Bureau of Statistics.

- 1965. Population and Housing Census 1961: Procedures and Definitions. Publication no. 25. Jerusalem: Central Bureau of Statistics.

- 1966. Population and Housing Census 1961: The Settlements of Israel, Part 6. Publication no. 28. Jerusalem: Central Bureau of Statistics.

- 1973a. Statistical Abstract of Israel. Jerusalem: Central Bureau of Statistics. 1973b. Immigration to Israel 1948-1972. Special Series no. 416. Jerusalem: Central Bureau of Statistics.

- 1974. The Standard Classification of Occupations 1972. Jerusalem: Central Bureau of Statistics.

Israel Manpower Planning Authority. 1964. Manpower in Development Towns. Jerusalem: Ministry of Labor.

Israel Ministry of Welfare. 1972. Settlements in Israel: Profiles. Jerusalem: Ministry of Welfare.

Lichfield, Nathaniel. 1971. Israel's New Towns: A Developmental Strategy. 3 vols. Jerusalem: Ministry of Housing.

Matras, Judah. 1973. "Israel's New Frontier: The Urban Periphery." In Israel: Social Structure and Change, edited by Michael Curtis and Mordecai Chertoff. New Brunswick: Transaction Books. 


\section{American Journal of Sociology}

Sicron, Moshe. 1957. Immigration to Israel (suppl.). Jerusalem: Central Bureau of Statistics.

Smith, Herbert. 1972. Survey of Development Towns and Cities. No. 1. In Hebrew. Jerusalem: Smith Center for Research.

Spiegal, Erika. 1966. New Towns in Israel. Stuttgart: Kramer.

Spiro, Melford E. 1970. Kibbutz: Venture in Utopia. New York: Schocken.

Stigler, George. 1966. The Theory of Price. New York: Macmillan.

Taeuber, Karl E., and Alma F. Taeuber. 1965. Negroes in Cities: Residential Segregation and Neighborhood Change. Chicago: Aldine.

Talmon, Yonina. 1972. Family and Community in the Kibbutz. Cambridge, Mass.: Harvard University Press.

U.S. Bureau of the Census. 1963. Census of Population 1960: Occupational Characteristics. Report no. PC(2)-7A. Washington, D.C.: Government Printing Office.

Weintraub, Dov, and M. Shapira. 1971. "The Family in the Process of Change: Crisis and Continuity." In Immigration and Social Change, edited by Dov Weintraub. Jerusalem: Israel Universities Press.

Zarchi, Shaul, and Aryia Shiskin. 1972. Qiryat Shimona: Establishment of a Development Town. In Hebrew. Jerusalem: Ministry of Housing. 